\title{
Cattle avoidance of leafy spurge: A case of con- ditioned aversion
}

\author{
SCOTT L. KRONBERG, RUSSELL B. MUNTIFERING, ELDON L. AYERS, AND \\ CLAYTON B. MARLOW
}

\begin{abstract}
Authors are former research associate, former associate professor, former research associate, and associate professor, respectively, Department of Animal and Range Sciences, Montana State University, Bozeman 59717.

S.L. Kronberg is currently with the USDA-ARS, U.S. Sheep Experiment Station, Dubois, Ida. 83423 and R.B. Muntifering is currently with the Alabama Agr. Exp. Sta., Auburn Univ., Alabama 36849-5403.
\end{abstract}

\begin{abstract}
Leafy spurge (Euphorbia esula $L$.) represents a serious threat to the productivity and profitability of many cattle ranches in the midwestern U.S. Sheep and goats will graze the weed, but cattle generally do not. We hypothesized that cattle avoid leafy spurge because it contains 1 or more chemicals that elicit a conditioned flavor aversion when consumed. First, we tested cattle to determine if they reduced their intake of a novel feed on subsequent days if we modestly increased rumen fill by introducing additional feed or additional feed plus an aversive agent (lithium chloride, $\mathbf{~ i C l}$ ) after they had consumed the novel feed. We observed that cattle became averted $(P=.0001)$ to the novel feed only when $\mathrm{LiCl}$ was administered with additional feed. Simply increasing rumen fill by a small amount did not cause cattle to reduce their intake of the novel feed the following day. Secondly, we tested cattle to determine if they reduced their intake of a novel feed on subsequent days if we introduced leafy spurge into their rumina following consumption of the novel feed. We also tested cattle to determine if a spurge-induced aversion to a novel feed was preventable by inoculation with rumen microbes from sheep with spurge in their diets. We found that introducing spurge into cattle after their intake of novel feed reduced $(P<.01)$ their intake of the novel feed on subsequent days. Cattle inoculated with rumen microbes from spurge-adapted sheep had similar $(P>.40)$ aversions to a novel feed paired with spurge introductions. Apparently, cattle avoid leafy spurge partly or wholly because they develop a conditioned aversion after first ingesting some threshold amount of it.
\end{abstract}

Key Words: noxious weeds, ruminants, food aversion learning

Leafy spurge (Euphorbia esula L.), an aggressive perennial weed from Eurasia, is seriously threatening the productivity and profitability of many range-based cattle operations in the United States. While sheep or goats may ingest and consequently help control the spread of spurge, cattle generally consume little, if any (Lym et al. 1988). It is commonly believed that spurge is harmful to cattle (Lacey et al. 1985, Lym and Kirby 1987), yet sheep and goats can sustain high productivity with considerable daily intake of growing spurge (Landgraf et al. 1984, Bartz et al. 1985, Lym et al. 1988). Their high productivity is likely a response to high crude protein (15-28\% of dry matter) and low acid detergent fiber (13-25\% of dry matter) levels in spurge's vegetative and flowering stages (Fox et al. 1991).

\footnotetext{
Funding for this research was provided in part by the Montana Department of Agriculture, Noxious Weed Trust Grant Number MDA 90-12.

The authors wish to express their appreciation to Mr. Robert Harrington for his assistance in conducting the trials.

Publication has been approved by the Director of the Montana Agr. Exp. Sta., Journal Series J-2831.

Manuscript accepted 1 Jan. 1993.
}

Small ruminant grazing can effectively check spurge expansion, but spurge abundance will increase if grazing is discontinued (Lacey et al. 1984). If cattle could be adapted to tolerate and graze spurge similarly to sheep or goats, then cattle, the predominant range livestock in the U.S., could be used to check the spread of this weed while utilizing it as forage. One obstacle in making this practice work is the potential of cattle forming aversions to spurge.

Burritt and Provenza (1989) demonstrated that sheep will develop conditioned aversions to novel feeds when these feeds are paired with negative post-ingestive consequences. We observed cattle consume small amounts ( $\leq 1 \mathrm{~kg}$ ) of pre-senescent spurge on range and in confinement for 1 or 2 days, then stop consuming it. Consequently, we speculated that cattle avoid leafy spurge because they develop a conditioned aversion to spurge after they first consume it.

We hypothesized that 1 or more aversive compounds in leafy spurge elicit negative post-ingestive consequences in cattle, and further that the aversive compounds in spurge could be modified or degraded before eliciting negative post-ingestive malaise. Ruminal microbes can degrade some plant toxins (James et al. 1975, Carlson and Breeze 1984), hence we reasoned that sheep may harbor 1 or more ruminal microbial species capable of metabolically altering potentially aversive compounds in spurge, while cattle may lack this capacity and are consequently averted to spurge.

In this paper, we report on 2 experiments designed to investigate aspects of cattle feeding behavior with respect to leafy spurge. The first experiment was designed solely to test part of the methodology used in the second experiment. The objective of the first experiment was to determine whether cattle will avoid or reduce their intake of a novel feed, simply because the bulk fill in their rumina is modestly increased by the introduction of additional plant material (ruminal fill was increased by a similar amount in both experiments), or if the introduction of an aversive chemical (e.g., lithium chloride) is necessary to elicit reduction in novel feed intake. The objectives of our second experiment were to determine whether the introduction of leafy spurge into cattle rumina causes conditioned feed aversion, and if we might prevent a spurgeinduced aversion by introducing ruminal digesta (with its compliment of microbes) from spurge-consuming sheep into cattle.

\section{Materials and Methods}

\section{Experiment 1}

Fifteen rumen-fistulated Hereford calves (mean wt, $181 \mathrm{~kg}$ ) were randomly divided into 3 treatment groups of 5 calves each. During the trial, Group-1 calves were dosed with alfalfa (Medicago sativa L.) pellets within 0.5 hour after consuming a novel feed (Vitality 
Milk Plus Pellets $\left.{ }^{1}\right)$. This feed is a highly palatable concentrate. Group-2 calves were dosed with alfalfa pellets plus lithium chloride ( $\mathrm{LiCl})(80 \mathrm{mg} / \mathrm{kg}$ body weight) within 0.5 hour after consuming the novel feed, while Group-3 calves did not receive post-consumption dosages after consuming the novel feed. Lithium chloride is an aversive agent which is quickly absorbed from the digestive tract (Harrison et al. 1963) and has been used in numerous studies to elicit conditioned taste aversions (Braveman and Bronstein 1985). Alfalfa pellets and $\mathrm{LiCl}$ were placed into calves' rumina through their fistulas.

For calves in Groups 1 and 2, the amount of alfalfa pellets placed in the rumen each trial day was equal to the weight of the novel feed they had consumed that day; $\mathrm{LiCl}$ was administered in the gelatin capsules. Each calf in Groups 1 and 2 was given alfalfa pellets or alfalfa pellets and $\mathrm{LiCl}$ on each trial day that it ingested any amount of the novel feed. Beginning on day 1 of the trial, 907 grams ( 2 pounds) of the novel feed were offered to each calf from 0800 to 0900 hours. The calves were tested for aversion to the novel feed on days $3,5,7$, and 9 following their initial exposure to the novel feed on day 1 . The amount of novel feed consumed by each calf was determined on each day.

In addition, all calves received a basal ration of alfalfa pellets sufficient to permit an average daily gain of $0.2 \mathrm{~kg}$ (NRC 1984). Calves were fed their basal ration in 2 equal feedings at 0900 and 1500 hours; this schedule was started 2 weeks prior to the initiation of the trials. Calves were allowed 1.5 hours to eat their basal ration, then were released into large pens with unlimited access to tracemineral salt and water.

\section{Experiment 2}

Fifteen rumen-fistulated Hereford calves (mean wt, $172 \mathrm{~kg}$ ) were randomly divided into 3 treatment groups of 5 calves each. Group1 calves received pre-trial inoculations of ruminal microbes (in digesta) from 2 adult sheep that had about $1 \mathrm{~kg} /$ day of fresh-cut leafy spurge (seed-development growth stage) in their diets for 2 weeks before ruminal digesta was collected. On 3 alternate days of the week preceding the trial, each calf in Group 1 received 200 $\mathrm{ml} /$ day of ruminal digesta from the sheep. On the mornings of these 3 days, about $750 \mathrm{ml}$ of ruminal contents were collected from each sheep. The 2 collections were pooled, mixed, and stored in an insulated container. Each calf received its portion within 0.5 hour after the digesta had been collected. Calves in Groups 2 and 3 did not receive pre-trial manipulations of their rumen environment. Calves in Groups 1 and 2 received spurge during the trial and Group-3 calves served as controls.

During the pre-trial period, calves received a basal ration of alfalfa pellets which were fed at a rate to permit an average daily gain of $0.2 \mathrm{~kg}$ (NRC 1984). Calves were fed their basal ration in 2 equal portions at 0800 and 1500 hours. The basal ration was fed for 2 weeks before the trial began. Calves were allowed 1.5 hours to eat their basal ration, then were released into large pens with unlimited access to trace-mineral salt and water.

During the trial, calves in Groups 1 and 2 had leafy spurge introduced into their rumina on each day that they consumed any amount of the novel feed (an alfalfa- and grain-based horse pellet). The novel feed was offered at 0800 hours in place of the basal ration. Calves were fed individually, and the amount of novel feed offered each calf equaled the weight of the basal ration they had been fed at 0800 hours during the pre-trial period. A quantity of fresh spurge, equal to the weight of novel feed consumed, was introduced into each calf's rumen within 2 hours after it consumed the novel feed. The dose of spurge was matched with the amount of

${ }^{1}$ Nutrena Feed Div.. Cargill, Minneapolis, Minn. 55440. Use of this product does no constitute an endorsement by the Montana Agr. Exp. Sta. novel feed consumed to provide the calves with a realistic intake ratio of novel feed to spurge. One-half of the daily basal ration was fed at 1500 hours.

Leafy spurge, in seed-development stage, was cut about $6 \mathrm{~cm}$ above the ground from rangeland at the Red Bluff Research Ranch, $56 \mathrm{~km}$ west of Bozeman, Mont. Spurge was hand-chopped into about $1.5 \mathrm{~cm}^{2}$ pieces before insertion into designated calves. The order in which the calves received chopped spurge was adjusted daily to control for potential change in chemical characteristics of spurge over the 2-hour period from harvest to treatment. Leafy spurge contains potentially inflammatory diterpenoid ingenols (Upadhyay et al. 1978; Seip and Hecker 1982) that may be the aversive agents for cattle. The chemical instability of ingenols is reported to be high in heat, light, oxygen, and alkaline or acidic conditions (Evans 1986); therefore we attempted to minimize the time between harvest and introduction of spurge into the cattle. The calves were tested for aversion to the novel feed on 5 consecutive days following their initial exposure to the novel feed on day 1 .

For both experiments, data for novel feed intake on day 1 were analyzed with analysis of variance as a completely randomized design with the General Linear Models (GLM) procedure of SAS (1988). Data for novel feed intake on subsequent days were first analyzed by analysis of covariance with novel feed intakes on day 1 as the covariate. If the covariate was not significant $(P>0.10)$, it was excluded from the model used for analysis of variance. Data for novel feed intake on subsequent days were analyzed using a repeated measures design and the GLM procedure of SAS (1988). Individuals were nested within treatment groups and the calf (treatment) mean square was the error term for the $F$ statistic for treatment. Data were balanced for both experiments. When appropriate, individual means were compared using the protected LSD procedure (SAS 1988).

\section{Results and Discussion}

\section{Experiment 1}

On the first day of the trial, novel feed intake was similar ( $P=$ 0.28 ) among calves in all 3 groups (Table 1). Novel feed intake on

\section{Table 1. Mean daily intakes $(g)$ of the novel feed $( \pm S E)$ for treatment} groups in Experiment 1.

\begin{tabular}{|c|c|c|c|c|c|}
\hline Group & Day & Day $3^{8}$ & Day $^{b}$ & Day $^{b}$ & Day $9^{b}$ \\
\hline $\begin{array}{l}1^{\mathrm{c}} \\
2^{\mathrm{d}} \\
3^{\mathrm{e}}\end{array}$ & $\begin{array}{l}907^{f} \pm 0 \\
884^{f} \pm 23 \\
895^{f} \pm 12\end{array}$ & $\begin{array}{r}907 \\
0 \\
907\end{array}$ & $\begin{array}{c}907^{\circ} \pm S E \\
84^{8} \pm 42 \\
907^{\mathrm{f}} \pm 0\end{array}$ & $\begin{array}{l}907^{f} \pm 0 \\
344^{g} \pm 212 \\
907^{f} \pm 0\end{array}$ & $\begin{array}{l}907^{f} \pm 0 \\
135^{\mathrm{s}} \pm 56 \\
907^{\mathrm{f}} \pm 0\end{array}$ \\
\hline
\end{tabular}

There was no variation in intakes among individuals in the 3 groups on day 3 therefore, analysis of variance was not conducted on data for this day. Calves in groups 1 and 3 ate all of the novel feed offered on these days. cGroup 1 calves received alfalfa pellets after they ate the novel feed.

dGoup 2 calves received alfalfa pellets after they ate the novel feed.
${ }^{\text {Group }} 2$ calves received alfalfa pellets and $\mathrm{LiCl}$ after they ate the novel feed.

Group 2 calves received alfalfa pellets and $\mathrm{LiCl}$ after they ate the novel feed.
'Group 3 calves received neither alfalfa pellets nor $\mathrm{LiCl}$ after they ate the novel feed. ${ }^{1-g}$ Means for the same day with different superscripts differ $(P<01)$.

day 1 was not a significant covariate $(P>0.20)$ in the models for novel feed intake on days $3,5,7$, and 9 . However, treatments had a strong effect $(P=0.0001)$ on novel feed intake on subsequent days of the trial. Individual days and the interaction of days with treatments were not important $(P>0.20)$ variables affecting novel feed intake. The group of calves that received $\mathrm{LiCl}(2)$ was the only group that was averted to the novel feed on the test days $(P<0.01)$. In contrast, calves in Groups 1 and 3 ate all of the novel feed offered on these days. Apparently, a small increase in rumen fill resulting from introduction of alfalfa pellets into Group- 1 calves had no negative effect on their consumption of novel feed. Our results agree with those of Olson and Ralphs (1986), who averted cattle to alfalfa pellets by ruminal infusions of lithium chloride or an extract 
from the poisonous plant tall larkspur (Delphinium barbeyi $\mathrm{L}$. Huth) after cattle had eaten alfalfa pellets. Their heifers developed strong and persistent aversions to alfalfa pellets by the fifth feeding paired with either type of infusion.

\section{Experiment 2}

On the first day of the trial, calves in all groups had similar ( $P=$ 0.70 ) intake of novel feed (Fig. 1). Novel feed intake on day 1 was not a significant covariate $(P<0.49)$ in the models for novel feed

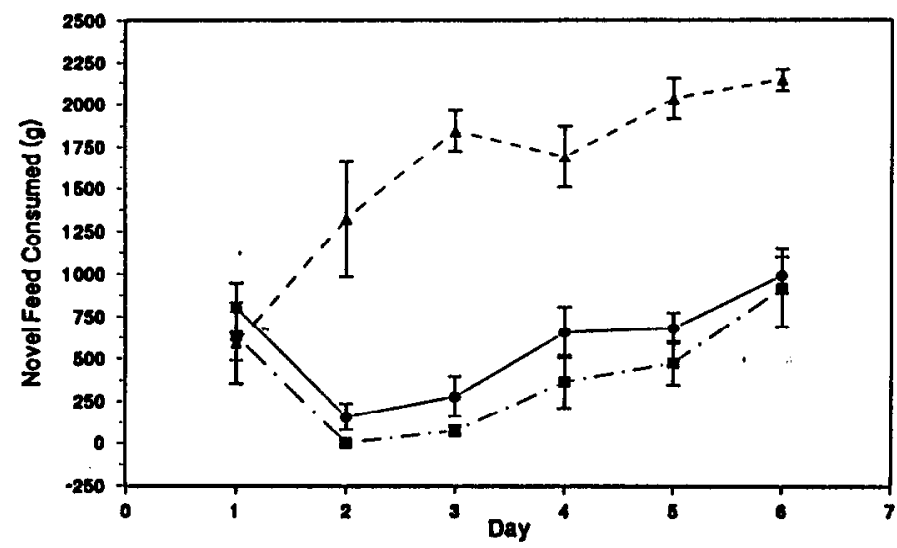

Fig. 1. Consumption of novel feed (g) during a 1-hour period by 3 treament groups of cattle on each day of a 6-day trial. Group 1 calves (- - -) received pre-trial inoculations of ruminal microbes (in digesta) from sheep that had leafy spurge in their diets and the calves received spurge each day shortly after they ate the novel feed. Group 2 calves $(-1-)$ did not receive a pre-trial treatment, but they received spurge each day shortly after they ate the novel feed. Group 3 calves $(-\Delta-)$ did not receive a pre-trial treatment and they did not receive spurge when they ate the novel feed. Bars represent $\pm \mathbf{S E}$.

intakes on days 2 through 6 . However, subsequent intakes varied $(P=0.0001)$ as functions of treatment and day; the day $\times$ treatment interaction was not significant $(P=0.41)$. Both groups that had received chopped spurge after consuming the novel feed on day 1 ingested less $(P=0.001)$ of the novel feed on day 2 than Group-3 calves that had not received spurge. Calves in Group 1 that received ruminal digesta from sheep were as averted $(P>0.17)$ to the novel feed as calves that received spurge without a rumen pre-treatment (Group 2).

Transferring ruminal digesta from sheep with spurge-containing diets did not prevent cattle from developing a spurge-induced aversion. This finding suggests that if sheep harbor ruminal microbes that can alter or degrade aversive chemicals in spurge and if we successfully transferred them, they may not be able to exist (or exist in sufficient numbers) in cattle rumina. Alternatively, ruminal microbes in cattle may produce an aversive substance from spurge, whereas sheep ruminal microbes may not. If this possibility occurs, transferring ruminal microbes from sheep to cattle would not alter the aversive response of cattle to spurge.

Calves that did not receive spurge (Group 3) ate increasing amounts of novel feed during the trial. After day 2, the groups that received spruge ate gradually increasing amounts of the novel feed. Their responses are similar to those observed by Burritt and Provenza (1989) with lambs offered $\mathrm{LiCl}$-treated or untreated corn, oats, or calf-manna, and to those of Provenza et al. (1990) with goats offered pellets of older-growth blackbrush (Coleogyne ramosissima Torr.) which had been coated with purified condensed tannins. There are several possible explanations for the increased intake of novel feed by calves which received spurge. First, calves may have developed a physiological tolerance to the aversive chemical(s) in spurge. Second, calves' ruminal microbes may have developed enhanced metabolic capacity to degrade aversive chemicals in spurge; consequently, calves may have absorbed lower levels of the aversive chemicals and had reduced levels of negative feedback. Finally, previous exposure to spurge may have sequentially reduced the level of post-ingestive malaise that calves experienced with each additional exposure to aversive compounds in spurge consequently, they experienced declining aversion to spurge. This preexposure effect has been discussed by Braveman (1977).

\section{Summary}

Aversions by calves to a novel feed were induced only when the aversive chemical $\mathrm{LiCl}$ was introduced following intake of the novel feed. Introduction of a small amount of additional forage into calves' rumina, with consequent increase in rumen bulk fill, did not reduce intake of the novel feed on subsequent days. The introduction of leafy spurge into cattle rumina elicited conditioned aversions to a novel feed they consumed. This finding suggests that cattle avoid spurge partly or wholly because they develop a conditioned aversion to it after intially ingesting some threshold amount. Introduction of ruminal digesta and microbes from sheep with spurge in their diets did not prevent cattle from developing a spurge-induced aversion.

\section{Literature Cited}

Bartz, S., B. Landgraf, P. Fay, and K. Havstad. 1985. Leafy spurge (Euphorbia esula) as a forage component for ewes and lambs. SID Res. Digest. Winter.

Braveman, N.S. 1977. What studies on pre-exposure to pharmacological agents tell us about the nature of the aversion-inducing treatment. $p$. 511-530. In: L.M. Barker, M. Best and M. Domjan (eds.) Learning mechanisms in food selection. Baylor Univ. Press, Houston, Tex.

Braveman, N.S., and P. Bronstein (eds.) 1985. Experimental assessments and clinical applications of conditioned food aversions. The New York Academy of Sciences, N.Y.

Burritt, E.A., and F.D. Provenza. 1989. Food aversion learning: ability of lambs to distinguish safe from harmful foods. J. Anim. Sci. 67:1732-1739.

Carlson, J.R., and R.G. Breeze. 1984. Ruminal metabolism of plant toxins with emphasis on indolic compounds. J. Anim. Sci. 58:1040-1049.

Evans, F.J. 1986. Environmental hazards of diterpene esters from plants, p. 1-31. In: Fred J Evans (ed.), Naturally occurring phorbol esters. CRC Press, Inc., Boca Raton, Fla.

Fox, D., D. Kirby, J. Caton, and R. Lym. 1991. Chemical composition of alfalfa and leafy spurge at four phenological stages of growth. Proc. of North Dakota Acad. of Sci. Abst.

Harrison, F.A., K.J. Hill, and J.L. Mangan. 1963. Absorption and excretion of lithium and magnesium in the sheep. Biochem. J. 89:99-100.

James, L.F., M.J. Allison, and E.T. Littledike. 1975. Production and modification of toxic substances in the rumen, p. 576-590. In: I.W. McDonald and A.C.I. Warner (eds.), Digestion and metabolism in the ruminant. Univ. New England Pub. Unit, Armidale, N.S.W., Australia.

Lacey, C.A., R.W. Kott, and P.K. Fay. 1984. Ranchers control leafy spurge. Rangelands 6:202-204.

Lacey, C.A., P.K. Fay, R.G. Lym, C.G. Messersmith, B. Maxwell, and H.P. Alley. 1985. Leafy spurge: distribution, biology and control. Montana State Univ. Coop. Ext. Serv. Cir. 309.

Landgraf, B.K., P.K. Fay, and K.M. Havstad. 1984. Utilization of leafy spurge (Euphorbia esula) by sheep. Weed Sci. 32:348-352.

Lym, R.G., and D.R. Kirby. 1987. Cattle foraging behavior in leafy spurge (Euphorbia esula)-infested rangeland. Weed Tech. 1:314-318.

Lym, R.G., C.G. Messersmith, and D.E. Peterson. 1988. Leafy spurge identification and control. North Dakota Ext. Serv. Cir. W-765.

NRC. 1984. Nutrient requirements of beef cattle (6th ed.). Nat. Acad. Press, Washington, D.C.

Olsen, J.D., and M.H. Ralphs. 1986. Feed aversion induced by intraruminal infusion with larkspur extract in cattle. Amer. J. Vet. Res. 47:1829-1833.

Provenza, F.D., E.A. Burritt, T.P. Clausen, J.P. Bryant, P.B. Reichardt, and R.A. Distel. 1990. Conditioned flavor aversion: a mechanism for goats to avoid condensed tannins in blackbrush. Amer. Natur. 136:810-825.

SAS. 1988. SAS/STAT user's guide. SAS Inst., Inc. Cary, N.C.

Seip, E.H., and E. Hecker. 1982. Skin irritant ingenol esters from Euphorbia esula. J. Med. Plant Res. 46:215-218.

Upadhyay, R.R., F. Bakhtavar, M. Ghaisarzadeh, and J. Tilabi. 1978. Cocarcinogenic and irritant factors on Euphorbia esula L. latex. Tumori 64:99-102. 